\title{
A PROBLEMÁTICA DA VIOLÊNCIA CONJUGAL EM MOÇAMBIQUE
}

\section{THE PROBLEM OF CONJUGAL VIOLENCE IN MOZAMBIQUE}

RESUMO: O artigo traz uma análise sociológica da violência conjugal em situação de relacionamento heteronormativo, fenômeno recorrentemente praticado em várias relações conjugais, sempre com a mulher como vítima. Para a operacionalização deste trabalho recorreu-se a pesquisa bibliográfica, análise documental e entrevistas informais com alguns atores sociais que dia a dia lidam e intervêm nestes casos, com intuito de melhor entender como é que se dá esta violência conjugal, para depois sugerir medidas de sua prevenção, devido as suas nefastas consequências, mormente para a saúde moral e psicológica dos envolvidos. A violência contra mulher representa uma grande inquietação para a sociedade moçambicana em particular e do mundo no geral. $O$ estudo visa identificar as possíveis causas desta violência para em seguida chamar atenção a sociedade civil a uma reflexão profunda sobre a nefastidade dessa problemática social, com vista a coibir a sua proliferação de geração em geração. Os resultados sugerem que a violência conjugal é uma realidade inegável e independe do nível de escolaridade dos envolvidos.

Palavras-chave: Gênero. Violência. Resiliência. Relação conjugal.
ABSTRACT: The article presents a sociological analysis of conjugal violence in a heteronormative sexual situation, a phenomenon recurrently practiced in various marital relations and with women as victims. For the operationalization of this work we resorted to bibliographic research, document analysis and informal interviews with some social actors who deal and intervene in these cases, with the intuition to better understand how this conjugal violence occurs, and then to suggest measures of their prevention, due to its harmful consequences, especially for the moral and psychological health of those involved. Violence against women is a major concern for Mozambican society in particular and the world at large. The study aims to identify the possible causes of this violence and then draw the attention of all civil society to a profound reflection on the harmfulness of this social problem, in order to curb its proliferation from generation to generation. The results suggest that marital violence is an undeniable reality and independent of the level of education of those involved.

Keywords: Gender. Violence. Resilience. Marital relationship.

\footnotetext{
${ }^{1}$ Mestranda em Direito pela Universidade Federal do Paraná (UFPR). Licenciada em Direito pelo Instituto Ciências e Tecnologias de Moçambique (ISCTEM). Bolsista CAPES. E-mail: leaofernandadosantos@gmail.com.

${ }^{2}$ Doutorando em Sociologia pela UFPR. Mestre em Counseling pela Universidade do Zimbabwe. Bolsista CAPES.
} 


\section{INTRODUÇÃO E CONTEXTUALIZAÇÃO}

A violência é um termo que deriva do Latim "violentia", que significa "veemência, impetuosidade". Trata se de um fenômeno histórico e patente desde o surgimento da humanidade e que vem se manifestando de formas diferenciadas em cada período histórico, podendo mudar de tonalidade. Ela é do domínio mundial, por se encontrar em todos os cantos do planeta, influenciada, sobretudo, por aspetos culturais, étnicas e políticos. Na contemporaneidade, pela sua prática acentuada e suas consequências nefastas, têm sido procuradas formas que possam explicar as causas deste fenômeno. Este fato social tem tornado apreensivo toda a sociedade em geral, com particularidade para a camada socioeconomicamente desfavorecida e de baixo nível de escolaridade. Esta violência pode se desdobrar se em vários tipos, dentre eles se destaca a simbólica e física, e isso atrela-se as suas carências advindas da ausência da sua empregabilidade em setores formais, tanto como informais de atividades. Para a Organização Mundial da Saúde (OMS, 2002), a violência constitui o uso doloso da força em uma forma de ameaça, contra si mesmo, outra pessoa, podendo ocasionar lesão, morte, dano psíquico, alterações do desenvolvimento ou privações.

A feminização da pobreza no país agudiza o maxismo e a prática diferenciada desta violência. A violência contra a mulher ocorre independendo da idade, status sociais, origem e religião. Ela tem-se manifestado de formas distintas, sendo que na maioria delas se encontra ligada à tradição, à cultura e da maneira como o homem e a mulher foram socializados. Nalgumas vezes por se tratar de algo que algumas culturas já institucionalizaram como forma de fazer acatar algumas normas ou como meio de corrigir algum comportamento tido desviante da sua companheira, o agressor acha se no direito de perpetuá-la, mostrando a sua masculinidade e mantedor de ordem no lar, em detrimento de outras formas educacionais dialogantes e pacíficas. De acordo com (Gabinete de Atendimento a Mulher Vítima de Violência Doméstica, 2014-2016), no país, em cada 10 mulheres, seis são vítimas desta brutalidade. A falta de conhecimento sobre os direitos da mulher, sua educação cultural, por um lado, por outro lado, a submissão ao seu 
esposo por este ser provedor de condições econômicas familiares, leva algumas mulheres a pautarem por um autêntico silêncio, independentemente de ter informação destes direitos, e assim, o fenômeno evolui de forma vertiginosa.

Outrossim, em da termos jurídicos, nota-se um avanço significativo na provação de variadas legislações pelo parlamento, embora a sua operacionalidade se mostre ainda infrutífera, dado a parcialidade na sua aplicação, para além da ausência do seu uso ao pé da letra, tal como apela o legislador e nesta sequência, dificilmente alcança-se os fins da pena (prevenção especial e geral da violência) por falta de eficácia e eficiência na sua aplicabilidade para coibir a perpetuação cotidiana deste fenômeno social que até hoje representa um fato de maior repugnância social pela forma brutal de como tem-se praticado.

\section{UNIÃO CONJUGAL, VIOLÊNCIA E SUA SUPERAÇÃO}

A união conjugal é enxergada tradicionalmente como uma dinâmica de relações amorosas entre indivíduos de sexos opostos, não acontecendo ao acaso, pois, o intuito desta relação é a procriação. Esta união pode depender de fatores individuais, interpessoais, econômicos, sociais e culturais (DINIZ, 2011). Na contemporaneidade, a relação conjugal tem sido caraterizada pelas transformações que vêm ocorrendo na sociedade moderna, influenciada pela globalização crescente, demandando pela igualdade do gênero em todas esferas sociais (BUTLER, 2003), resultado da emancipação feminina e da inserção igualitária da mulher no mercado de trabalho e na partilha de responsabilidades familiares, como consequência de várias lutas sociais travadas durante muito tempo, através dos chamados movimentos sociais feministas. A noção da união conjugal a partir da modernidade, passa necessariamente pela instauração de uma intimidade entre os envolvidos na relação, colocando-a como condição para edificação de uma relação profícua, o que traduz se fundamental ideia de complementaridade entre os parceiros (MAGALHÃES; FÉRES-CARNEIRO, 2003).

A demanda pela satisfação na relação conjugal, tem sido uma das responsáveis pela influência na escolha de cônjuge (SILVA et al., 2010). Esse ensejo complementar é resultado de alguns aspetos inatos de natureza humana que sempre deixam de ter um 
desenvolvimento completo durante a formação da personalidade de cada indivíduo, sendo assim, ele procura enxergá-lo na mulher ou no homem aquém deseja ter uma relação conjugal. Ainda outra causa encontra se ligada a similaridade, que é a procura no outro, de perfil semelhante a àquele que o indivíduo encontra em sim mesmo (Idem).

Em todo o processo de formação da união conjugal, dois aspetos são de suma importância, nomeadamente: (i) O individualismo e (ii) conjugalidade. O individualismo é inerente a questões de natureza individual, referindo se aos modos de ser e estar, imbuídos nas crenças, na cultura na perspetiva de vida, ao passo que a conjugalidade liga se a aspetos amorosos, e segundo Féres-Carneiro (2003, p. 2), trata-se de uma componente psicológica comungada por parceiros que tem uma dinâmica inconsciente em relação as leis e funcionamento peculiares de uma relação conjugal. Representando anseio conjugado de formação de um histórico de vida em comum, numa autêntica construção de uma identidade da vida conjugal (MENEZES; LOPES, 2007).

Por outro lado, a dinâmica entre esses aspetos, tem-se caracterizado por diversas tensões, dado que convive-se num meio social onde se prioriza o individualismo nas relações, em detrimento da partilha de objetivos conjugais, ou seja, em cada um dos constituintes da relação conjugal, mostra se apreensiva em atender de forma prioritária os seus anseios e objetivos (ZORDAN et al., 2009). Em várias relações conjugais, as dificuldades de formar uma união conjugal vai de acordo com as habilidades de aprimorar a conciliação da perspetiva individual com a perspetiva conjugal, de modo que o projeto seja de ambos, evitando desconfianças infundadas entre o casal. Como é normal o aparecimento de conflitos entre o casal, este deve ser dirimido por meio de diálogo, sem recorrência ao uso de qualquer tipo de violência, o que infelizmente não acontece em maior parte dos casais. Neste contexto, Paiva (2009) adverte que em caso de conflito conjugal advindo das diferenças é importante que ambos pautem por via diálogo de forma pacífica e compreensiva, de modo a negociar para que a relação se fortifique. Esta paciência mútua na resolução de diferenças existentes faz com que haja reciprocidade no estabelecimento da identidade conjugal, sem que esta desfaça a identidade existente em cada um dos constituintes do casal (CHAVES, 2011). Os constituintes de um casal saudável 
para que não percam a sua individualidade conjugal, eles adotam uma estratégia de incluir a visão do outro nas suas perspetivas.

A agudização das diferenças individuais dos constituintes do casal ocorre mercê das mutações que tem acontecido nas sociedades contemporâneas, onde as ideologias do gênero têm trazido este individualismo, confundindo se com autonomia em relações amor diferenças de individualidades dos parceiros conjugais, tem sido acentuadas pelas mudanças que vêm/veem ocorrendo na sociedade contemporânea, particularmente os ideais amorosos em uniões conjugais (VIEIRA; STENGEL, 2011). Na contemporaneidade, as expectativas de uma união conjugal vão para além do interesse de procriar, como obter a felicidade, sucesso individual, simples prazer sexual, companheirismo, não obstante a distribuição mais igualitária de funções e papeis conjugais diários (DINIZ, 2011).

Esta transformação funcional equitativa da mulher contemporânea não é algo linear e vinculativa para todas mulheres, pois, existem mulheres que mesmo conhecendo dos seus direitos sempre se deixaram subordinar ao homem, mercê da educação enraizada na cultura conservadora. Desta feita, frisar que, tanto o homem como a mulher levam consigo para a união conjugal influências emanadas de suas famílias de origem, desde hábitos, valores, tradição, costumes e até herança afetivo-emocional (DINIZ, 2011; GUAMBE, 2015), que condicionam em grande medida, como cada elemento da união conjugal se comportará em termos de posições durante a convivência conjugal.

O bom panejamento das perspetivas do casal depende muito, sobretudo das negociações constantes, franco diálogo, confiança e compreensão mútua. Estes quesitos constituem um balão de oxigênio para derrotar qualquer tipo de conflito conjugal que possa surgir em qualquer fase da convivência matrimonial, fortificando cada vez mais a relação entre ambos. Ademais, cada elemento da relação conjugal tem obrigações mútuas, como manter se calado quando está aborrecido para evitar palavrões descontroladas, planos conjuntos, cuidar um do outro, podendo ser em tempos de crises ou abundância, evitar a recusa de sexo, salvo em situações melhor justificadas, mudança de rotina, na manifestação de procedimentos saudáveis afetivos em convívio conjugal. Não obstante ao panejamento conjunto dos objetivos e expectativas dos cônjuges, gestão financeira do 
casal, respeitar a liberdade individual e tanto como cuidar dos filhos, mantendo sempre uma relação profícua com a família dos ambos (DINIZ, 2011).

A negociação conjugal para que surta efeitos desejáveis é crucial que nela esteja patente a compreensões, confiança mútua e adaptações constantes à novas dinâmicas impostas pela globalização, claro, em função bem do casal, ou seja, interesses individuais devem estar debaixo dos interesses coletivos (CHAVES, 2011). Embora se saiba que a maioria das negociações patentes em uniões conjugais se dá de forma salutar, por outro lado, existem as que desaguam em violência letal e com consequências irreparáveis para a vítima, devido a morte ou lesões corporais graves em um dos integrantes da relação conjugal, com maior frequência na mulher como potencial vítima destas atrocidades domésticas (ALVIM; SOUZA, 2005). A vida prática tem demonstrado que ausência de abertura entre casais, origina desconfianças sem que haja razão para tal, tornando deste modo difícil definir o status de cada constituinte da relação conjugal durante a convivência cotidiana., tendo em conta que cada um caminha conforme a sua socialização familiar, aprendizado esse guiado pelos hábitos, crenças e costumes culturais sobre papéis de homem/ mulher numa relação conjugal que em muitas vezes esses hábitos e crenças são conflitantes.

A má interpretação da recente ideologia de género difundida por conceituadas teóricas feministas, Simone de Beauvoir (1986) em sua obra intitulada Ledeuxième sexo ["segundo sexo" na tradução nossa] e Judith Buther (2003) com a sua obra intitulada: Problemas de gênero: feminismo e subversão da identidade, fez com que as relações conjugais heteronormativas degradassem consideravelmente, vivendo se num mundo em que reina a solteirice, no contexto da famosa expressão "minhas contas pago eu" e como não bastasse, as relações homoafetivas tendem a ganhar terreno um pouco por todo o mundo acompanhadas por atos homofóbicos. A pesar destas recentes teorias de gênero terem sido expandidas, apelando a igualdade de tratamento entre homens e mulheres, nota-se haver cada vez mais mulheres tornando-se vítimas, independentemente do seu status socioeconómico, ou seja, nestas relações conjugais tem ocorrido várias tipologias de violência, muitas vezes por obsessividade de um dos cônjuges. 


\section{PERCURSO DE UM ATO CONJUGAL VIOLENTO E SUAS CONSEQUÊNCIAS}

A violência conjugal por ser um fenômeno de natureza social, encontra-se disseminada um pouco por toda a esfera terrestre, tanto em casais considerados estáveis, tanto como em pares de simples namorados (GOMES et al., 2000; PAZO; AGUIAR, 2012), na maioria dos casos motivada por ciúmes ou por inconformidade com o fim do relacionamento. Para a Organização Mundial da Saúde-OMS (2012), considera se a violência conjugal toda a conduta que em uma relação íntima, tende a provocar danos físicos, sexual, psicológicos e morais a um ou a todos cônjuges. Outros autores conceituam a violência conjugal como ato brutal que ocorre entre indivíduos com uma relação de intimidade sexual, por meio de imposição de força física (HIRIGOYEN, 2006).

O termo violência é polissémico dependendo da cultura, ou seja, um ato pode ser considerado violento por uma cultura e por outra cultura como algo normal, daí que tem tornado difícil evitar a sua proliferação, devido a existência de indivíduos que possam preservá-la por ser algo que regula a sua convivência social. A violência contra a mulher deixa marcas insaráveis na vida dela e caso não seja atendida por um psicólogo, pode tornar se uma patologia psíquica de difícil reparação, daí que é fundamental que as vítimas ou abusos de género sejam prontamente atendidas por um profissional da área da psicologia por forma a destraumatizá-la através de aconselhamento e diversas formas terapêuticas. Esta violência entre cônjuges pode manifestar se de maneiras dolosas diferentes, partindo de maneiras simples, como a dita violência psicológica até as mais notáveis por deixar marcas indeléveis, quer psicológicas, quer fisicamente (DINIZ, 2013). A psicológica, refere se a é um tipo de natureza silenciosa, na sua maioria as suas vítimas encontram maiores entraves ou obstáculos em encará-las como uma violência real em curso e mesmo sentindo se ofendida opta em perdoá-lo na esperança de que o parceiro mudará de comportamento. A violência psicológica é o ponto de partida para a violência física, pois, a maioria dos homens violentos, começa preparando o terreno, ameaçando a parceira e em caso de notar que não conseguiu alcançar seus intentos que é ofendê-la, recorre já para a força física, uma vez que está deixa dores de forma imediata, o que torna irresistível por qualquer vítima (HIRIGOYEN, 2006). As consequências psicológicas variam desde prejuízos emocionais, redução de autoestima, perturbações mentais, físicas e social 
e pode consistir em constranger, humilhar, manipulações, isolar, controle abusivo, insultar, chantagear, limitar a circulação e ridicularizar contra a parceira.

Por ser um fato complexo e não deixar marcas visíveis no corpo, os autores de violência psicológica quando denunciados pela vítima, sempre negaram o seu envolvimento, para além de que ninguém se digna a testemunhar os fatos junto as entidades responsáveis pela aplicação da lei, em virtude de apenas terem simplesmente ouvido falar da agressão e não terem nenhum momento presenciá-la, o que leva a impunidade dos transgressores diante da justiça formal (HIRIGOYEN, 2006). Como se disse anteriormente o termo violência é polissémico, porque o seu significado depende de quem faz sua interpretação, de acordo com as crenças culturais de cada comunidade, por exemplo um ato numa determinada cultura pode ser socialmente repugnante e legalmente punido, mas em contrapartida o mesmo ato na outra comunidade pode ser considerado normal e profícua sob o ponto de vista educacional, sendo assim, mesmo que a lei sancione, ninguém da comunidade se digna a denunciá-lo. Casos de mutilação genital, prática cultural em alguns países da África, mas em outros países são socialmente repugnante e severamente punido como lesões corporais. Nestes países que consideram este ato como uma cultura, dificilmente denunciam, alegadamente por recearem serem considerados de indivíduos com condutas desviantes por rebelarem contra uma crença generalizada e acreditada por todos (CASIQUE; FUREGATO, 2006).

A física, refere se a comportamentos que ofende a integridade física do indivíduo, chamando a atenção da vítima pela dor que sente ao ser atingida por ela, trata se de agressões físicas, mutilações genitais, execuções, etc. (DINIZ, 2013). No entender de Hirigoyen (2006), ela inclui, dentre outras ofensas corporais: pancadas, chutos, empurrões, mordidelas, queimação, socos, pontapés, etc.

Outro tipo de violência conjugal corriqueiramente praticada e menos denunciada por receio de vexame é a sexual, entendida como uma conduta que obriga a parceira a praticar relações sexuais contra sua vontade, por meio de ameaça ou aplicação da força física, abrange também a proibição de exercício de direitos sexuais reprodutivos a parceiras (DINIZ, 2013). É uma violência na qual as parceiras têm-se deparado com empecilhos quanto a abordagem sobre seus direitos reprodutivos, por achar ser algo 
vergonhoso. Em muitos casos que ocorrem, um ato sexual forçoso, raramente é denunciado pela vítima, por ela considerar como um dever que ela tem para com o seu parceiro, independentemente da sua disposição (HIRIGOYER, 2006)

Ainda outra violência contra a mulher mais praticada na visão de Diniz (2013) é a patrimonial, compreendida como a conduta que consiste em reter, subtrair total ou parcialmente bens que se destinam a satisfação das necessidades da parceira e dos filhos, consistindo na destruição de todo o tipo de patrimônio do casal, com o único fim prejudicar a mulher e aos seus dependentes (DINIZ, 2013). Faz igualmente parte desta violência, a financeira que se liga a pressão econômico-financeira, que quando feita retira a independência da parceira (HIRIGOYEN, 2006). Ademais, alguns homens não concedem de forma satisfatória as despesas familiares e em caso da mulher exercer uma atividade econômica, o homem opta em controlar todos os seus rendimentos, direcionando a sua aplicação (HIROGOYEN 2006). Para o autor, muitas mulheres desempregadas, por falta de outra forma de sustento financeiro, optam em coabitar com um parceiro violento e insuportável, mesmo perante um notável desgaste da relação conjugal. Até algumas mulheres vítimas temo mínimo para sobreviver, mas porque o homem é empossado e deves enquando oferece presentes como carros, as mulheres acabam se seduzindo ao ponto de substituir os maus tratos por bens materiais com o receio de perdê-los caso ela decida pela separação.

\section{GÊNERO, SEXO E VIOLÊNCIA CONTRA MULHER EM UNIÃO CONJUGAL}

Variadas pesquisas científicas realizadas por diversos estudiosos, concluíram que uma parte considerável de violência em uma relação conjugal é praticada por indivíduos do sexo masculino contra suas companheiras e quase todas motivações encontram se ligadas ao machismo e ao consumo de álcool e outras drogas proibidas (ALVIM; SOUZA, 2005; HIRIGOYEN, 2006; LAMOGLIA; MINAYO, 2009). Quanto as teorias feministas, a violência entre cônjuges é denominada de violência de gênero (NARVAZ; KOLLER, 2006).

Conforme as teorias feministas, o termo sexo, remete nos a algo de nascença, inata ou então podemos dizer que estamos perante algo de carater biológico e representa algo fisiológico que diferencia um homem e uma mulher. Por seu lado, gênero é uma 
construção social e cultural, ou seja, caraterísticas que qualquer pessoa pode escolher a seu bem prazer para melhor se identificar socialmente (SCCOTT, 1995; BUTLER, 2003). Assim, o gênero é uma categoria social que define papéis durante as complexas relações sociais, políticas, econômicas e psicológicas entre homens e mulheres na sociedade (BUTLER, 2003).

Em Moçambique, existem dois sistemas de relações de poderes entre homens e mulheres, notadamente: sistema patriarcal e sistema matriarcal. Cada sistema é guiado pelas suas crenças culturais peculiares. Na região centro e norte do país, concretamente nas províncias de Zambézia e Tete no centro; Nampula, Cabo Delegado e Niassa no norte, funciona o sistema matriarcal, caraterizado por ritos de iniciação, que representa momento de transmissão de conhecimentos e práticas que orientam a transição da infância a adolescência e desta para a vida adulta, desempenhando um papel preponderante na construção da identidade feminina, sobre como conviver bem em uma relação amorosa. No sistema matriarcal a voz da mulher é mais privilegiada do que a de um homem, por exemplo é normal um homem casar e morar em casa da esposa, ao passo que em um sistema patriarcal pela força da cultura patriarcal é um grave absurdo. Nestas cerimónias as meninas veem na obrigação de ver seus clítoris puxados e os homens são submetidos a circuncisão, que é a remoção da pele que encobre o prepúcio, como forma por se encontrada de preparar o homem para uma atividade sexual futura. É nestas cerimónias que se institucionalizam os valores e crenças de um adulto, que permitam o reconhecimento do poder masculino sobre o feminino, construindo assim, a sexualidade masculina e feminina numa relação de poder. A sexualidade masculina circunscreve se na liberdade sexual e na demonstração de virilidade em relação ao homem, enquanto a sexualidade feminina é uma construção da repressão caraterizada por prescrições de impedimentos (OSÓRIO, 2013).

Por outro lado, na parte sul do país (Maputo, Gaza e Inhambane, e Sofala, Manica no centro do país, funciona o sistema patriarcal, caraterizado por "machismo", os meninos são incutidos um espirito machista, um poder de dominação sobre a mulher, prover bens alimentares para a família. Por seu lado, as meninas são preparadas a cuidar do seu futuro esposo e das crianças que por dever deve procriar, uma vez que que o sistema de relações 
conjugais moçambicano é heteronormativo (TVEDTON et al., 2010). Essa educação é transmitido durante a socialização primária, ou seja, no seio familiar. Nesta transmissão de papéis de gênero, há uma relação de poder diferenciada entre mulher e homem, caraterizada pelo poder de dominação do homem sobre a mulher.

A formação social de funções de gênero de acordo com o sexo fez com que houvesse uma concepção diferente e hierárquica entre a masculinidade e a feminilidade, atravessando a história, fazendo presente em todos âmbitos da vida social e a nível cultural. Neste caso, os papéis masculinos são enxergados como sendo os mais valiosos, ao passo que os papéis da mulher são tidos de domínio privado, virando se para os cuidados do marido e dos filhos que tem por obrigação procriar (CASQUE; FUREGATO, 2006).

É neste diapasão que dissemos que a violência infligida contra a mulher é apadrinhada por uma série de construtos sociais, no qual constrói-se valores e espaços diferenciados dos homens e das mulheres, o que propicia a permanência do homem numa posição de poder sobre as mulheres. Essas construções sociais feitas durante a socialização acaba influenciando grandemente nas interações entre homens e mulheres durante relações conjugais, marcando profundas desigualdades entre ambos.

\section{GÊNERO E VIOLÊNCIA CONJUGAL NO PATRIARCADO}

A ideologia de gênero indaga e problematiza valores culturais nas relações interpessoais e sociais. Para Alencar e Cantera (2012) e Pazo e Aguiar (2012), a violência masculina contra mulheres é conceituada como sendo um ato de excesso de poder, resultado de uma estrutura social que legitima os homens agridam as suas parceiras, num sistema patriarcal. No sistema patriarcal existe uma legitimação institucional autoritária do homem sobre sua parceira (AGUIAR; DINIZ, 2010), neste caso essa estrutura hierárquica construída culturalmente dá privilégio a todas atividades do homem em detrimento as das mulher.

Na parte centro e sul de Moçambique, como já se disse anteriormente, pela cultura patriarcal existente, a menina desde sua tenra idade deve praticar brincadeiras típicas de uma mulher (brincar com brinquedos feminizados, jogar neca, cozinhar etc.) e o menino, a de um homem (caçar, jogar a bola). Neste caso, em meio familiar, os meninos exercem um 
controle comportamental sobre as meninas, mesmo quando adultas, por se considerar que o homem é sempre um legítimo herdeiro do património familiar, ou seja, desde pequena, o pai ou um irmão dela exerce essa função zeladora e quando casada o controle passa a ser exercido pelo marido. É impressionante constatar que mesmo sendo o irmão mais novo, ele sempre assume esse papel vigiador da irmã, porque o que importa é poder enraizado na masculinidade.

De acordo com Carvalho-Barreto et al. (2009), no sistema patriarcal, o homem exerce o poder de dominação transmitido pelo sistema sob prévio consentimento da mulher. Uma parte da violência contra a mulher emana do seu controle abusivo pelo homem, caraterizando se pela manifestação de uma imposição de restrições, começando por fazer impedimentos absurdos a mulher para que não prossiga com seus estudos, para que não trabalhe, para não saia de casa, para que não visite sua família, entre outras. Ainda é corriqueiro que o homem decida sobre a forma de vestir da sua parceira, tipo de amizade que ela deve ter e com quem (AGUIAR; DINIZ, 2010).

Neste caso, se a mulher mostrar uma resistência em acatar tais decisões, demonstrando uma independência, por exemplo, o homem passa a utilizar sobre ela meios aterrorizantes que até podem ser letais. O ciclo vicioso da violência conjugal gera um espirito de perdão constante como se algo vai bem e sendo assim, o termino sempre tem sido um autêntico pesadelo para a mulher, daí é premente que ela tome previdência cabível logo que inicia o primeiro ato violento contra ela (CARVALHO-BARRETO et al., 2009).

O mais impressionante é que no sistema patriarcal, o homem para ficar com a sua esposa deve imediatamente se submeter a uma série de cerimónias, onde será cobrado uma quantia em valores monetários ou em outros bens materiais, alegadamente para alegrar espíritos dos antepassados da noiva e todos os filhos que brotarem da relação pertencem a família do homem, ao passo que no sistema matrilinear não se cobra dinheiro, senão um garrafão de vinho e terno para os pais e para os avós da noiva, mas os filhos que surgirem do casal pertencem automaticamente a família da mulher. Portanto no sistema patriarcal, a mulher deve se submeter totalmente ao seu marido, numa situação de uma alienação total (DINIZ; PONDAAG, 2004). 
A feminização da pobreza, através da exclusão da mulher em áreas socialmente relevantes, tais como área econômica, política e social, dificulta a sua plena participação ativa e consequentemente retira a sua aparição e reconhecimento como atora socialmente relevante na área produtiva (DINIZ; PONDAAG, 2004). No âmbito familiar, ela desempenha múltiplas atividades, dentre elas a de cuidar do marido, procriar e educação dos filhos, para além de cuidar de familiares colaterais dela e do marido.

As comunidades tradicionalmente conservadoras enxergam na mulher um objeto de prazer e de procriação e automaticamente vê nela sua propriedade, cabendo ele fazer tudo o que lhe apetece quando e como quiser (IOP, 2009; SAFFIOTI, 1999). Por exemplo na província nortenha de Cabo Delgado, as petizes quando estão na fase da puberdade são severamente submetidas aos tradicionais "ritos de iniciação", onde são instruídas sobre como se lidar com a sua vida adulta, que muitas vezes se consubstanciam na sua vulnerabilidade a sujeição a práticas escravas de seus futuros esposos, por meio de aprendizagem do tipo: o homem tem todo o direito de pedir sexo e, nós é só aceitar, é obrigatório - fala de uma jovem que passou pelos ritos de iniciação (MARIANA, 2018).

Essa fala demonstra como a prática da sexualidade pode ser ensinada e vivida de forma violenta, fazendo parte de um conjunto de deveres que a mulher deve cumprir. No processo de socialização as mulheres são instruídas a serem pacientes e tolerantes para com as atitudes e desejos de seus maridos. Elas devem assumir que é vergonhoso contar ou reivindicar algo que aconteça na relação conjugal. A atitude mais louvável é calar-se e assumir o seu sofrimento (SAGIM et al., 2007). O modo silêncio como as mulheres se apresentam é tido por elas como uma arma fundamental para evitar que as desavenças conjugais não atrapalhem as relações matrimoniais, aliás, o silêncio é uma alternativa de evitar possível prática de violência contra a parceira.

O entendimento estereotipado de funções masculinos e femininos faz com que as mulheres admitam a necessidade de aguentar os maus tratos infligidos pelo seu parceiro, com o fito de salvaguardar o bem-estar de seus filhos (DINIZ; PONDAAG, 2004). A interiorização desses valores, futuramente, limita as chances delas fazerem revoltas conta atitudes violentas de seus esposos, por terem institucionalizados essas crenças submissas. Os meninos são instruídos a serem provedores de condições econômicas familiares e como 
entidade emanante de normas a serem seguidas no seio familiar (OSÓRIO, 2013). Em caso de uma desobediência no cumprimento destas normas, o esposo de e prerrogativa de devolver a companheira junto a sua família, afim de ser reeducada pelos seus pais.

A compreensão de gênero como constructo social e cultural faz entender que a violência entre cônjuge não tem raízes sexuais parceiros, mas sim como algo histórico produzido e reproduzido pelas estruturas sociais de dominação, reforçado pela ideologia patriarcal.

\section{VIOLÊNCIA CONJUGAL E FATORES DE RISCOS ASSOCIADOS}

Os fatores de riscos são eventos negativos que quando presentes no contexto pessoal, relacional e social, aumentam a possibilidade de a pessoa apresentar problemas físicos, psicológicos e sociais (POLLETO; KOLLER, 2011). A idade dos cônjuges está associada ao risco de prática de violência conjugal, todavia, não existe unanimidade entre os pesquisadores. No caso particular de Moçambique, ser jovem constitui um fator de risco para as mulheres sofrerem violência praticada por parceiros íntimos, situação agravada pelos casamentos contraídos em tenra idade, fato muito comum em zonas rurais de Moçambique, o que contribui para elevar casos de violência conjugal.

A relação entre o nível de escolaridade e a violência praticada pelo parceiro íntimo constitui um outro fator de risco de natureza complexa. Deeke et al. (2009) indicam que a violência pode ser praticada ou sofrida por indivíduos com qualquer nível de escolaridade.

Os estudos de Zacarias et al. (2012) concluíram que na cidade de Maputo, as mulheres com nível de formação média ou superior, sofreram mais violência comparativamente às que não sabem ler nem escrever. A expectativa que se tem é que as mulheres com maior nível de educação sejam mais assertivas e encarem a relação conjugal com outras perspectivas e, consequentemente, os seus parceiros notam o seu poder e capacidade de controle ameaçado, o que os leva a recorrer à violência, como meio de se impor.

Os dados apresentados parecem indicar que as mulheres que não tiveram nenhum tipo de educação formal, podem melhor corresponder às exigências culturais do ser mulher. Por essa via elas podem ser totalmente obedientes aos seus parceiros o que 
garante o exercício do domínio sobre elas. Vale exaltar que é importante considerar as particularidades do contexto conjugal.

\section{CONSIDERAÇÕES FINAIS}

O presente artigo trouxe à superfície as desigualdades vividas entre homens e mulheres na relação conjugal, como reflexo do sistema patriarcal na construção social dos papéis de gênero, que atribui aos homens uma posição de poder hegemónico em relação às mulheres. Homens e mulheres socializados no sistema patriarcal tendem a reproduzir no seu cotidiano certas condutas que concorrem para a violência entre os cônjuges.

Suportados pela hegemonia masculina, os parceiros das mulheres vítimas de violência, alegam que assumem o papel de disciplinadores, sempre que julgarem que o comportamento da mulher está fora das regras impostas por eles, embora em muitos casos sem motivo aparente.

Numa sociedade em que vigoram as normas do patriarcado entre os cônjuges, entende que a homem casa a mulher "compra". Por essa via, ele adquire os direitos sobre ela. Esse tipo de concepção leva ao homem a considerar a sua esposa como parte da sua propriedade. Nessas circunstâncias, não tem cabimento a mulher apossar da casa, porque ela apenas se configura com um simples bem do marido.

Alguns líderes religiosos representam um fator de risco para a perpetração da violência, mormente quando apelam as mulheres a preservarem os seus matrimónios. Muitas vezes convencem-nas que com a fé em Deus os problemas se resolvem do que recorrer à justiça formal. Com base nesses ensinamentos muitas mulheres mantêm-se em relacionamentos violentos à espera que um milagre opere mudanças no comportamento dos parceiros.

O fator cultural, como génese no patriarcado e nas prescrições sociais de gênero também se mostram influentes na atuação de alguns profissionais de serviços públicos (governantes e operadores do sistema de justiça criminal). Muitas vezes é notória a tendência de banalizar o sofrimento da mulher, o que revela um sentimento e crenças pessoais desses funcionários em relação ao lugar da mulher na sociedade. Influenciados 
por esses ideais, os serviços públicos mostram-se fragilizados e não cumprem com o seu papel de ajudar a mulher que sofre da violência.

O papel da comunidade varia em função das interpretações dadas aos problemas conjugais. No caso em que a comunidade se distancia do problema, isso representa um fator de risco para a mulher que sofre de violência. Responsabilidade pelo combate à violência de género deve ser de toda a sociedade. Deve estar presente na família, nas diversas instituições sociais, em todos os níveis de formação escolar, instituições do Estado, tais como os serviços sociais e jurídicos, delegacias da Polícia, nas instituições religiosas. Todos devem dirigir ações no combate às diversas formas de manifestação da violência.

Cada família deve ser orientada a atuar em prol da eliminação da desigualdade na socialização dos meninos e das meninas em diversas culturas. É igualmente importante que homens e mulheres, jovens de ambos os sexos, meninos e meninas, sejam envolvidos em programas de sensibilização. Tais programas devem contribuir para o entendimento de diversas formas de manifestação da violência, de modo particular aquela que é praticada contra a mulher em função da desigualdade de gênero. Esse processo deve ter em vista uma mudança de mentalidade.

A minimização da violência contra a mulher não só passa necessariamente pela introdução de legislações com penas pesadas, mas também é necessário que estas penas previstas, embora brandas, sejam aplicadas ao pé da letra sem contemplações, para servir de prevenção geral, que é uma das finalidades das penas.

Sugere se a criação de leis com um caráter mais educativo e não necessariamente punitivo, para salvaguardar de forma profícua a relação do casal, evitando o divórcio que é pernicioso para vida social dos filhos. 


\section{REFERÊNCIAS}

AGUIAR, L. H. M.; DINIZ, G. R. S. Género, masculinidade e atendimento a homens autores de violência conjugal. In: LIMA, F. R.; Santos, C. Violência doméstica: vulnerabilidade e desafios na intervenção criminal e multidisciplinar. Rio de Janeiro: Lumen Juris Ltda., 2010.

ALENCAR, R.; CANTERA, L. Violencia e Género en la parejo: una revisión teórica. PSICO, Porto Alegre, v. 43, n. 1, p. 116-126, 2012.

ALVIM, S. F.; SOUZA, L. Violência conjugal em uma perspetiva relacional: homens e mulheres agredidos/agressores. Psicologia Teórica e Prática, v. 7, n. 2, p. 171-206, 2005.

BEAUVOIR, Simone. Deuxieme Sexe. Paris: Gallimard Education, 1986.

BUTHER, Judith. Problemas de gênero: feminismo e subversão da identidade. Rio de janeiro: Editora Civilização Brasileira, 2003.

CARVALHO-BARRETO, A. et al. Desenvolvimento humano e violência de género: uma integração biológica. Psicologia: Reflexão e crítica, v. 22, n. 1, p. 86-92, 2009.

CASIQUE, L. C.; FUREGATO, A. R. F. Violência contra mulher: reflexões teóricas. Rev. LatinoAM Enfermagem, v. 14, n. 6, 2006.

CHAVES, R. O significado do sentimento de amor na contemporaneidade: a perspetiva da mulher. Monografia (Curso de Psicologia), Centro Universitário Franciscano, Santa Maria, 2011.

DEEKE, L. P. et al. A dinâmica da violência doméstica: uma análise a partir de discursos da mulher agredida pelo seu parceiro. Caderno de Saúde Soc. , São Paulo, v. 18, n. 2, p. 248258, 2009.

DINIZ, G.; PONDAAG, M. Explorando significados de silêncio e do segredo no contexto de violência doméstica. In: MALUSCHKE, G.; BUCHER-MALUSCHKE, J. S. N. F.; HERMANNS, K. (org). Direitos humanos e violência: desafios da ciência e da prática. Fortaleza: Fundação Konrad Adenauer, 2004.

DINIZ, G. Até que a vida - ou a morte - os separe: análise de paradoxos de relações violentas. In: FÉRES-CARNEIRO, T. (org.). Casal e família: transmissão, conflitos e violência. São Paulo: Casa do Psicólogo, 2013.

DINIZ, G. Conjugalidade e Violência: reflexão sob a áptica de género. In: FÉRES-CARNEIRO, T. (org.). Casal e família: transmissão, conflitos e violência. São Paulo: Casa do Psicólogo, 2011.

GOMES, N. et al. Compreendendo a violência doméstica a partir das categorias de género e de gerações. Acta Paulista de Enfermagem, v. 20, n. 4, p. 504-50, 2009.

GUAMBE, Maria de Lurdes Gilberto. Dinâmica conjugal violenta e resiliência em mulheres assistidas na CÁ-PA. Dissertação (Mestrado em Psicologia), Maputo, 2015. 
HIRIGOYEN, M. F. A violência no casal: da coação psicológica a agressão física. Trad. M. H. Kuhner. Rio de Janeiro: Bertrand Brasil, 2006.

IOP, E. Condição da mulher como propriedade em sociedades patriarcais. Visão Global, Joaçaba, v. 12, n. 2, 2009.

MAGALHÃES, A. S.; FÉRES-CARNEIRO, T. Conjugalidade e subjetividades contemporâneas: o parceiro como instrumento de legitimação do "eu". In: ENCONTRO MUNDIAL ESTADOS GERAIS DA PSICANÁLISE, 2. Anais [...], Rio de Janeiro, 2003.

MENEZES C. C.; LOPES, R. C. A transição para o casamento em casais coabitantes e em casais não coabitantes. Rev. Bras. Crescimento e Desenvolvimento Humano, v. 17, n. 1, p. 52-63, 2009.

MINAYO, M. C. S. O desafio do conhecimento: pesquisa qualitativa em saúde. 12. ed. São Paulo: Hucitec, 2009.

MOÇAMBIQUE. Relatório do Gabinete da Mulher e Criança Vítima de Violência Domestica. Maputo, 2014.

MOÇAMBIQUE. Relatório do Gabinete da Mulher e Criança Vítima de Violência Domestica. Maputo, 2016.

NARVAZ, M. G.; KOLLER, S. H. Mulheres vítimas de violência doméstica: compreendendo subjetividades assujeitadas. PSICO, Porto Alegre, v. 37, n. 1, p. 7-13, 2009.

OMS. Prevenção da violência sexual e da violência pelo parceiro íntimo contra mulher: ação e produção de evidência. 2012. Disponível em: www.who.int/iris/bitstream. Acesso em: 12 dez. 2017.

OSÓRIO, C. Identidade de género e identidades sexuais nos ritos de iniciação no Cento e no Norte de Moçambique. Outras Vozes, n. 43-44, 2013.

PAZO, C. G; AGUIAR, A. C. Sentidos de violência conjugal: análise de banco de dados de um serviço telefónico anonimo. Physis - Revista de Saúde Coletiva, Rio de Janeiro, v. 22, n. 1, p. 253-273, 2012.

POLLETO, M; KOLLER, S. H. Resiliência: uma perspetiva conveitual e histórica. In: DELL'AGLIO, D. D.; KOLLER, S. H.; YUNES, M. A. M. (org.). Resiliência positiva: interfaces de riscos à proteção. 2. ed. São Paulo: Casa da Psicologia, 2011.

SAFIOTTI, H. I. B. Já se mete colher em briga de marido e mulher. São Paulo em Perspetiva, v. 13, n. 4, 1999.

SILVA, I. M. et al. Em busca da "cara-metade": motivação para a escolha do cônjuge. Estudos de Psicologia, Campinas, v. 27, n. 3, p. 383-391, jul./set. 2010.

TVEDTON, I. et al. Género Pobreza no Sul e Moçambique. Relatório do Instituto Chr Michelsen, 2010.

VIEIRA, E. D.; STENGEL, M. Os nós do individualismo e da conjugalidade na Pós Modernidade. Aletheia, n. 32, p. 147-160, maio/ago. 2010. 
ZACARIAS, A. E. et al. Intimate partner violence against women in Maputo CytiMozambique. BMC International Health and Human Rights, 2012. Disponível em: http://www.biomedcentral.com. Acesso em: 12 dez. 2017.

CEZERILO, Fernanda Amélia dos Santos Leão; FRANZE, José Joaquim. A problemática da violência Conjugal em Moçambique. RBSD - Revista Brasileira de Sociologia do Direito, v. 7, n. 1, p. 33-51, jan./abr. 2020. 